\title{
APLIKASI PEMBANGKIT LISTRIK MIKROHIDRO UNTUK PENERANGAN LINGKUNGAN MASYARAKAT DI KECAMATAN CIWIDEY KABUPATEN BANDUNG
}

\author{
Bahtiar, A., Hidayat, D., Mindara, J.M., Syakir, N dan Wibawa, B.M. \\ Fakultas Matematika dan Ilmu Pengetahuan Alam Universitas Padjadjaran \\ E-mail: ayi.bahtiar@phys.unpad.ac.id
}

\begin{abstract}
ABSTRAK
Pembangkit Listrik Tenaga Mikrohidro atau PLTMH merupakan suatu sistem pembangkit listrik skala kecil yang menggunakan tenaga air sebagai tenaga penggeraknya seperti, saluran irigasi, sungai atau air terjun alam dengan cara memanfaatkan ketinggian dan debit air. Semakin tinggi ketinggian dan debit air maka semakin besar energi air yang dapat diubah menjadi energi listrik Mikrohidro dapat pula memanfaatkan ketinggian air yang tidak terlalu besar, misalnya dengan ketinggian air 2,5 meter untuk menghasilkan daya listrik 400 Watt. Relatif kecilnya energi yang dihasilkan mikrohidro dibandingkan dengan PLTA skala besar, PLTMH memiliki implikasi pada relatif sederhananya peralatan serta kecilnya areal yang diperlukan untuk instalasi, pengoperasian mikrohidro dan tidak menimbulkan kerusakan lingkungan, sehingga cocok untuk menjangkau ketersediaan jaringan energi listrik di daerahdaerah terpencil dan pedesaan.

Program PPM Prioritas ini membuat sistem PLTMH menggunakan selokan untuk pengairan sawah dan kebun sayuran dan mengaplikasikannya untuk lampu penerangan jalan di Kampung Tutugan, Kampung Tutugan, Desa Cisondari Kecamatan Ciwidey Kabupaten Bandung. Lokasi tersebut dipilih, karena memiliki sungai yang mengalir dari pengunungan ke daerah lembah dan memiliki potensi untuk dikembangkan sebagai sumber PLTMH. Penerangan jalan terutama di malam hari sangat diperlukan untuk meningkatkan akses masyarakat dan pengguna jalan, karena akses jalan menuju daerah tersebut sangat sempit dan melalui turunan serta tanjakan yang berbelok dan curam serta rawan kecelakaan. PLTMH yang dikembangkan menggunakan sistem turbin yang diputar dengan air yang disalurkan dari selokan melalui pipa dengan ketinggian 20 meter dan kemiringan 30 derajat, sehingga mampu menghasilkan daya listrik diatas 300 Watt. Lampu penerangan yang sudah terpasang adalah sebanyak 10 buah dengan daya 100 Watt dan sisanya masih dapat digunakan untuk peralatan listrik lain. Penerangan ini diharapkan mampu meningkatkan akses masyarakat ke daerah tersebut terutama pada malam hari. Masih diperlukan optimasi sistem turbin untuk meningkatkan daya listrik luaran yang dihasilkan.
\end{abstract}

kata Kunci: Pembangkit listrik, tenaga mikrohidro, energi listrik-daerah terpencil, ramah lingkungan

\section{ABSTRACT}

Microhydro power plant or PLTMH is a small-scale power generation system that uses water power as its driving force, such as irrigation canals, rivers or waterfalls nature by utilizing its height and discharge water. The higher altitude and water discharge water, the greater the energy that can be converted into electrical energy Microhydro can also be generated from medium heigh of the water level, for example, with a height of 2.5 meters of water to produce electrical power of 400 Watts. Relatively small microhydro energy produced compared to the large-scale hydropower
(PLTA), PLTMH has implications on relatively simple equipment and small required area for installation, simple operation and also no environmental damage, making it suitable to reach the network availability of electrical energy in remote and rural areas.

The PPM Priority Program of Universitas Padjadjaran developes PLTMH system by applying irrigation sistem for rice fields and vegetable gardens and apply it for street lighting in the Kampung Tutugan, Desa Cisondari, Kecamatan Ciwidey, Kabupaten Bandung. This location was chosen, because it has a small irrigation canal that flows from high position to the valley and has adequate potential to be developed as a source of PLTMH. Street lighting is highly needed to improve public access and road users, especially at night, because the access road to the area is very narrow and through derivatives and turns and steep climbs and accident-prone. The developed PLTMH was built by using turbine system that is rotated by water channeled through pipes from the canal with a height of 20 meters and a slope of 30 degrees, so it can generate electric power above 300 watts. Lights that have been installed are as many as 10 lamps with a power of 100 Watt and the rest can still be used for other electrical equipment. Street lighting is expected to improve public access to the area, particularly at night, so that could also boost the economy of the surrounding community. Some optimizations of the system are still required to improve the generated output electrical power.

Key word: Microhydro power plant, elektrical energy, remote area, enviromental

\section{PENDAHULUAN}

Pembangkit Listrik Mikrohidro atau dikenal sebagai Pembangkit Listrik Tenaga Mikrohidro (PLTMH) merupakan suatu sistem pembangkit listrik skala kecil yang menggunakan tenaga air sebagai tenaga penggeraknya seperti, saluran irigasi, sungai atau air terjun alam dengan cara memanfaatkan ketinggian dan debit air (Anonim (2008). PLTMH secara teknis terdiri dari tiga komponen utama yaitu air sebagai sumber energi, turbin dan generator atau pembangkit. Mikrohidro memperoleh energi listrik dari aliran air yang memiliki perbedaan ketinggian tertentu dengan memanfaatkan energi potensial jatuhan air. Semakin tinggi jatuhan air maka semakin besar energi potensial air yang dapat diubah menjadi energi listrik (Serway and Jewett 2004). Di samping faktor letak sungai, tinggi jatuhan air dapat pula diperoleh dengan membendung aliran air sehingga permukaan air menjadi tinggi (Anonim, 2003). Air dialirkan melalui pipa atau saluran air kedalam rumah pembangkit yang pada umumnya dibagun di bagian tepi sungai untuk menggerakkan turbin. Energi mekanik yang berasal dari putaran poros turbin akan diubah menjadi energi listrik oleh sebuah generator (Serway and Jewett 2004). Mikrohidro dapat pula memanfaatkan ketinggian 
air yang tidak terlalu besar, misalnya dengan ketinggian air 2,5 meter untuk menghasilkan daya listrik 400 Watt U. Hendar 2007.

Relatif kecilnya energi yang dihasilkan mikrohidro dibandingkan dengan PLTA skala besar, memiliki implikasi pada relatif sederhananya peralatan serta kecilnya areal yang diperlukan untuk instalasi dan pengoperasian mikrohidro. Hal tersebut merupakan salah satu keunggulan mikrohidro, yakni tidak menimbulkan kerusakan lingkungan. Perbedaan antara Pembangkit Listrik Tenaga Air (PLTA) dengan mikrohidro terutama pada besarnya tenaga listrik yang dihasilkan, PLTA dibawahukuran 200KW digolongkan sebagai mikrohidro. Dengan demikian, sistem pembangkit mikrohidro cocok untuk menjangkau ketersediaan jaringan energi listrik di daerah-daerah terpencil dan pedesaan., Indartono 2008.

\section{METODE}

Metode pembuatan PLTMH dilakukan melalui beberapa tahapan, yaitu survey lokasi, desain peralatan PLTMH, uji coba dan instalasi. Survey lapangan diperlukan untuk mengetahui potensi air sebagai sumber listrik, mengukur debit air yang akan digunakan sebagai input bagi perancangan PLTMH, saluran air yang digunakan dan tempat penempatan turbin. Tahapan desain meliputi desain dan perancangan sistem turbin, generator, rumah panel dan instalasi. Tahapan ujicoba dilakukan di Departemen Fisika untuk mensimulasikan sistem PLTMH dan ujicoba peralatan sebelum diinstal di lapangan. Sedangkan instalasi di lapangan dilakukan untuk ujicoba secara riil.

\section{Tujuan Kegiatan}

Target kegiatan PPM Prioritas ini adalah membuat sistem Pembangkit Listrik Tenaga Mikrohidro (PLTMH) yang menghasilkan daya listrik luaran 500 Watt. Listrik yang dihasilkan digunakan untuk lampu penerangan jalan di sekitar lokasi PLTMH yang minim di malam hari sehingga akses masyarakat menjadi terhambat.

ProgramPPMPrioritas iniadalah untuk merancang PLTMH dan mengaplikasikannya untuk penerangan jalan di Desa Cisondari Kecamatan Ciwidey Kabupaten Bandung. Luaran dari PPM ini berupa teknologi tepat guna (TTG) sistem pembangkit listrik mikrohidro yang mampu menghasilkan listrik di bawah 500 Watt.

Hasil dari kegiatan ini diharapkan mampu meningkatkan akses terutama di malam hari sehingga mampu meningkatkan perekonomian masyarakat. Disamping itu, kegiatan ini dapat digunakan untuk mentransfer ilmu dan teknologi tepat guna kepada masyarakat di sekitar lokasi PLTMH, khususnya generasi muda. Sistem ini juga dapat dijadikan sebagai acuan untuk membuat sistem PLTMH di daerah atau lokasi yang berbeda dengan biaya yang lebih murah dibandingkan dengan sistem yang tersedia secara komersial. Transfer teknologi sangat diperlukan karena sistem PLTMH bergantung pada sumber air dan lokasi. Pengembangan PLTMH ini diharapkan mampu memotivasi masyarakat untuk mengembangkan sistem secara swadaya dalam upaya penyediaan listrik secara mandiri, terutama untuk masyarakat di daerah yang tidak teraliri oleh listrik dari PLN, namun memiliki potensi untuk dikembangkan pembangkit listrik mikrohidro.

\section{Manfaat Kegiatan}

Hasil dari kegiatan ini diharapkan mampu meningkatkan akses terutama di malam hari sehingga mampu meningkatkan perekonomian masyarakat. Disamping itu, kegiatan ini dapat digunakan untuk mentransfer ilmu dan teknologi tepat guna kepada masyarakat di sekitar lokasi PLTMH, khususnya generasi muda. Sistem ini juga dapat dijadikan sebagai acuan untuk membuat sistem PLTMH di daerah atau lokasi yang berbeda dengan biaya yang lebih murah dibandingkan dengan sistem yang tersedia secara komersial. Transfer teknologi sangat diperlukan karena sistem PLTMH bergantung pada sumber air dan lokasi. Pengembangan PLTMH ini diharapkan mampu memotivasi masyarakat untuk mengembangkan sistem secara swadaya dalam upaya penyediaan listrik secara mandiri, terutama untuk masyarakat di daerah yang tidak teraliri oleh listrik dari PLN, namun memiliki potensi untuk dikembangkan pembangkit listrik mikrohidro.

\section{SUMBER INSPIRASI}

Dengan mempertimbangkan keunggulan mikrohidro di antaranya tidak menimbulkan kerusakan lingkungan dan juga dengan mempertimbangkan kondisi daerah pelaksanaan kegiatan pengabdian kepada masyarakat yaitu tersedianya sungai yang mengalir dari pengunungan ke daerah lembah dengan aliran air memiliki debit yang cukup untuk dimanfaatkan sebagai sumber air, maka sistem pembangkit mikrohidro merupakan alternative yang tepat untuk membangun jaringan energi listrik PLTMH di daerah tersebut. Kampung Tutugan, Desa Cisondari Kecamatan Ciwidey Kabupaten Bandung memiliki sungai yang mengalir dari pengunungan ke daerah lembah yang pada umumnya dimanfaatkan untuk pengairan sawah dan kebun. Aliran air memiliki debit yang cukup untuk dimanfaatkan sebagai sumber air PLTMH. Di samping itu, listrik di daerah tersebut sangat kecil, umumnya masyarakat hanya memiliki listrik dengan daya 450 Watt setiap rumah, sehingga tidak cukup untuk lampu penerangan di jalan. Jalan untuk menuju daerah lokasi sangat sempit, turunan dan tanjakan yang terjal dan tidak memiliki lampu penerangan jalan. Dengan demikian, akses ke daerah tersebut sangat sulit terutama di malam hari dan rawan kecelakaan. Karena itu pengembangan PLTMH sangat diperlukan untuk meningkatkan akses ke daerah tersebut terutama di malam hari.

\section{KARYA UTAMA}

Target kegiatan PPM Prioritas ini adalah membuat sistem Pembangkit Listrik Tenaga Mikrohidro (PLTMH) yang menghasilkan daya listrik luaran 500 Watt. Listrik yang dihasilkan digunakan untuk lampu penerangan jalan di sekitar lokasi PLTMH yang minim di malam hari sehingga akses masyarakat menjadi terhambat.

Program PPM Prioritas ini adalah untuk merancang PLTMH dan mengaplikasikannya untuk penerangan jalan di Desa Cisondari Kecamatan Ciwidey Kabupaten Bandung. Luaran dari PPM ini berupa teknologi tepat guna (TTG) sistem pembangkit listrik mikrohidro yang mampu menghasilkan listrik di bawah 500 Watt.

Hasil dari kegiatan ini diharapkan mampu meningkatkan akses terutama di malam hari sehingga 
mampu meningkatkan perekonomian masyarakat. Disamping itu, kegiatan ini dapat digunakan untuk mentransfer ilmu dan teknologi tepat guna kepada masyarakat di sekitar lokasi PLTMH, khususnya generasi muda. Sistem ini juga dapat dijadikan sebagai acuan untuk membuat sistem PLTMH di daerah atau lokasi yang berbeda dengan biaya yang lebih murah dibandingkan dengan sistem yang tersedia secara komersial. Transfer teknologi sangat diperlukan karena sistem PLTMH bergantung pada sumber air dan lokasi. Pengembangan PLTMH ini diharapkan mampu memotivasi masyarakat untuk mengembangkan sistem secara swadaya dalam upaya penyediaan listrik secara mandiri, terutama untuk masyarakat di daerah yang tidak teraliri oleh listrik dari PLN, namun memiliki potensi untuk dikembangkan pembangkit listrik mikrohidro.

\section{ULASAN KARYA}

Sistem PLTMH menggunakan turbin sangat bergantung pada debit dan laju air dari sumber. Dalam sistem yang dikembangkan, air dialirkan menggunakan pipa agar menghasilkan laju yang tinggi, namun pipa yang digunakan harus lurus dan memiliki kemiringan yang tinggi. Laju air yang dihasilkan mampu memutar turbin dengan kecepatan putaran diatas 150 putaran per menit. Laju putaran ini dikonversi menggunakan roda dengan kombinasi rasio 6:1, sehingga mampu memutar generator dengan laju putaran diatas $600 \mathrm{rpm}$. Putaran ini masih di bawah putaran minimum generator yaitu 1400 rpm untuk menghasilkan tegangan listrik AC diatas 100 Volt dan arus listrik diatas 3 Ampere. Sistem yang dibuat mampu menghasilkan tegangan luaran $\mathrm{AC}$ dari generator sebesar 50-60 Volt, namun arusnya masih 1 Ampere. Hal ini diakibatkan oleh putaran generator yang masih kecil, sehingga diperlukan kombinasi roda dengan rasio 10:1 agar mampu memutar generator dengan kecepatan putaran lebih dari $1000 \mathrm{rpm}$.

Disamping itu, sistem yang dikembangkan menggunakan konversi listrik AC yang dihasilkan oleh generator menjadi DC untuk mengisi baterai dan selanjutnya dikonversi dengan inverter DC-AC untuk menghasilkan tegangan listrik 220 Volt sesuai dengan tegangan listrik yang dihasilkan oleh PLN. Penggunaan dua kali sistem konversi ini mengakibatkan kerugian daya (loss-power), sehingga daya listrik luaran sistem PLTMH menjadi berkurang. Diperlukan optimasi sistem terutama konversi putaran turbin ke putaran generator agar generator menghasilkan tegangan listrik diatas 100 Volt, sehingga tidak memerlukan lagi konversi AC ke DC dan inverter DC ke AC. Dengan demikian daya luaran yang dihasilkan menjadi tinggi.

\section{SIMPULAN}

Melalui kegiatan pengabdian kepada masyarakat tersebut telah berhasil dibuat dan diinstal sistem Pembangkit Listrik Tenaga Mikrohidro di Kampung Tutugan, Desa Cisondari, Kecamatan Ciwidey, Kabupaten Bandung yang digunakan untuk lampu penerangan jalan. Daya yang dihasilkan adalah diatas 300 Watt, namun dalam sistem PLTMH yang dikembangkan menggunakan baterai untuk menyimpan listrik dari turbin dan generator, sehingga walaupun daya listrik yang dihasilkan masih rendah tapi mampu digunakan untuk peralatan listrik dengan daya di atas 300 Watt.

\section{PENGHARGAAN}

Ucapan terima kasih disampaikan kepada pimpinan dan akademika LPPM Unpad, Divisi KKNM-PPMD Integratif LPPM Unpad, pemilik dan pembina Pesantren Duriyat Mulia, Bapak Pudjo Rahardjo, Ustadz Nurjeni dan Ustadz Ade Sutisna atas bantuannya terutama dalam penggunaan lahan untuk PLTMH dan bantuan pengerjaan sistem PLTMH, sehingga pekerjaan ini dapat selesai tanpa kendala berarti .

\section{DAFTAR PUSTAKA}

Anonim, 2003. Pedoman Pengelolaan Pengoperasian dan Pemeliharaan PLTMH Leuwi Kiara, Kabupaten Tasikmalaya, Dinas Pertambangan dan Energi Bandung.

Anonim, 2008. Manual Pembangunan Pembangkit Listrik Tenaga Mikrohidro, IBEKA-JICA Jakarta.

Hendar, U. 2007, Desain, Manufacturing dan Instalasi Turbin Propeller Open Flume Ø 125 Mm di CV Cihanjuang Inti Teknik CimahiJawa Barat, Fakultas Teknologi Pertanian IPB Bogor.

Indartono, Y.S. 2008, Krisis Energi di Indonesia: Mengapa dan Harus Bagaimana, http:// io.ppijepang.org/old/article.php?id=104 (diakses 10 Desember 2014).

Serway R.A. \& Jewett, J.W. 2004. Physics for Scientist and Engineer; $6^{\text {th }}$ Edition, Thomson Brooks/Cole USA. 